\title{
TERAPIA IMUNOSSUPRESSORA NO TRANSPLANTE DE FÍGADO: CONTRIBUIÇÃO PARA A ENFERMAGEM
}

\author{
IMMUNOSUPPRESSIVE THERAPY IN LIVER TRANSPLANTATION: CONTRIBUTION TO NURSING
}

\author{
Raphael Colares de Sáa, Camilo Reuber de Sousa Soares ${ }^{b}$ \\ arapha.colares@hotmail.com, bcamilo.reuber@hotmail.com \\ Universidade Federal do Ceará - Fortaleza (CE), Brasil
}

Data de recebimento do artigo: 17/03/2016 Data de aceite do artigo: 10/05/2016

\section{RESUMO}

Introduçáo: Todos os pacientes submetidos ao transplante de fígado necessitam de tratamento ao longo da vida com medicamentos imunossupressores com o intuito de evitar a rejeição do enxerto. Objetivos: $\mathrm{O}$ presente estudo tem por objetivo caracterizar a terapia imunossupressora utilizada no transplante de fígado e propor intervençôes de enfermagem ao manejo deste grupo terapêutico. Métodos: Trata-se de uma pesquisa documental e bibliográfica, de caráter descritivo, realizada a partir dos protocolos clínicos de transplante de fígado das instituiçôes transplantadoras do estado do Ceará. A partir dos protocolos, identificaram-se os imunossupressores utilizados no transplante de fígado e estes foram caracterizados a partir da literatura especializada e atualizada na área de medicina e farmacologia. Procedeu-se ainda com a discussáo sobre o adequado manejo dessa terapia pela equipe de enfermagem a partir das evidências das bases Micromedex e UpToDate. Resultados: Os agentes imunossupressores possuem características específicas relacionadas às suas indicaçôes, aos mecanismos de ação, aos efeitos adversos e às interaçóes medicamentosas, no qual o conhecimento e compreensão dessas características são fundamentais ao manejo da terapia visando à adequada função do enxerto. Nesse cenário, a equipe de enfermagem possui responsabilidades náo apenas na administração dos imunossupressores, mas também em monitorar os resultados, prever complicaçôes e na educação em saúde dos pacientes e familiares. Conclusóes: $\mathrm{O}$ manejo dos imunossupressores exige profissionais de enfermagem embasados cientificamente no que concerne às suas características e aos seus cuidados relacionados, a fim de garantir uma terapia segura e eficaz, como suporte para o paciente com orientaçôes pertinentes, garantindo seu empoderamento no próprio processo de cuidar.

Palavras-chave: Transplante de fígado; imunossupressores; enfermagem.

\section{ABSTRACT}

Introduction: All patients undergoing liver transplantation require lifelong treatment with immunosuppressive agents in order to avoid graft rejection. Objective: This study aims to characterize the immunosuppressive therapy used in liver transplantation and propose nursing interventions to manage this therapeutic group. Method: This is a documental, bibliographical and descriptive research conducted from clinical protocols of liver transplantation from the transplant centers of Ceará, Brazil. From the protocols, the immunosuppressive agents used in liver transplantation were identified and then characterized about its clinical and pharmacological characteristics from the specialized and current literature in the field of medicine and pharmacology. It then proceeded with the discussion about the proper management of this therapy by the nursing team from the evidences of Micromedex and UpToDate bases. Results: Immunosuppressive agents have specific characteristics related to their indications, mechanisms of action, adverse effects and drug interactions, in which knowing and understanding these characteristics are fundamental to the management of the therapy aiming to an adequate graft function. In this scenario, the nursing team has responsibility not only in the administration of immunosuppressive agents, but also in monitoring the results, preventing complications and promoting health education for patients and families. Conclusions: The management of immunosuppressive agents requires nursing professionals scientifically grounded about the characteristics and related care in order to ensure a safe and effective therapy, as in to support the patient with relevant guidelines, thus ensuring their empowerment in the process of self-care.

Keywords: Liver Transplantation; immunosuppressive agents; nursing. 


\section{Introdução}

O transplante de fígado (TF) configura-se como um recurso terapêutico para os indivíduos portadores de doença hepática terminal irreversível, assim como os casos de falência hepática aguda, desordens metabólicas hereditárias e alguns casos de malignidade envolvendo o fígado, como o carcinoma hepatocelular $(\mathrm{CHC})^{1,2}$.

Para a seleção dos receptores inscritos na lista de espera, utiliza-se como critério o sistema de pontuação Model for End-stage Liver Disease (Meld), aplicado para determinar a gravidade da doença hepática, indicando a probabilidade de morte nos próximos três meses, utilizando-se de um cálculo matemático baseado nos resultados dos exames de bilirrubina total, relação normalizada internacional (INR) e creatinina. Esse cálculo gera uma pontuação que varia de 6 a 40 pontos, no qual quanto maior a pontuação, mais grave o paciente é considerado ${ }^{3}$.

$\mathrm{O}$ primeiro TF do mundo foi realizado no dia $1^{\circ}$ de março de 1963, por Starzl et al, em um menino de 3 anos de idade com atresia biliar. Cinco anos depois, em 1968, Machado e sua equipe realizam o primeiro TF no Brasil ${ }^{2}$.

A partir de entáo, esse procedimento vem aumentando significantemente no país, alcançando um total de 1.755 TF realizados no ano de 2014 , o que representa uma média de 9,2 transplantes/por milhão de população (ppm). Nesse cenário, o estado do Ceará foi responsável por aproximadamente $11,1 \%$ desses transplantes, com um total de 195 procedimentos, mantendo a segunda posição dentre os estados brasileiros em número absoluto de TF. Nesse mesmo ano, apenas os estados do Ceará e do Distrito Federal apresentaram taxa de transplante superior a $20 \mathrm{ppm}$. Contudo, apesar do crescente número de doadores efetivos e de TF realizados no Brasil, esses números ainda estão muito aquém da necessidade estimada de receptores de fígado, que no ano de 2014 chegou a 4.769 pessoas em lista de espera ${ }^{4}$.

$\mathrm{O}$ sucesso nos TF ocorreu devido à evolução de três fatores primordiais: a padronização de técnicas cirúrgicas, o uso de soluçóes de preservação de órgãos e o surgimento dos medicamentos imunossupressores ${ }^{3}$, este revolucionando os resultados dos transplantes a partir da descoberta da ciclosporina e do tacrolimo nas décadas de 1970 e 1980 respectivamente, levando a excelentes taxas de sobrevida do enxerto em um ano ${ }^{5}$.

Por conseguinte, todos os pacientes submetidos ao TF necessitam de tratamento ao longo da vida com medicamentos imunossupressores com o intuito de evitar a rejeição do enxerto. No entanto, seu uso está associado a uma ampla gama de efeitos adversos relacionados a seus mecanismos de ação. Assim, a meta ideal da terapia é alcançar um equilíbrio entre a proteção contra a rejeição e a prevenção de seus efeitos adversos ${ }^{6,7}$.

Nesse cenário, a equipe de enfermagem, sob supervisão do enfermeiro, tem atuação imprescindível, uma vez que o preparo e a administraçáo de medicamentos é uma de suas atividades rotineiras e de responsabilidade legal da equipe, ocupando papel de destaque na função terapêutica a que o paciente está submetido, logo, cabem à equipe a detecção precoce e a prevenção de riscos e de possíveis complicaçóes advindas da terapia medicamentosa ${ }^{8}$.

Portanto, uma vez que a imunossupressão representa um dos pontos-chave para o sucesso do transplante, torna-se relevante garantir a segurança no processo de administraçáo da terapia imunossupressora por meio da facilitação dos conhecimentos técnicos científicos atualizados aos profissionais de enfermagem, especialmente os que concernem à farmacologia.

Assim, este estudo justifica-se pela necessidade de contribuir junto da comunidade científica e de enfermagem a respeito da caracterizaçáo farmacológica dos imunossupressores e seus cuidados de enfermagem relacionados, a fim de minimizar os riscos do tratamento.

Portanto, configurou-se como objetivo desta pesquisa caracterizar a terapia farmacológica imunossupressora utilizada no TF e propor intervençóes de enfermagem ao manejo desse grupo terapêutico.

\section{Método}

O presente estudo trata-se de uma pesquisa documental e bibliográfica, de caráter descritivo, realizado a partir dos protocolos clínicos de TF das instituiçóes hospitalares transplantadoras dessa modalidade do estado do Ceará, que atualmente possui três instituições transplantadoras de fígado. Dessas instituiçóes, uma trata-se de um hospital público universitário federal (Hospital A), outra de um hospital público estadual (Hospital B) e a terceira, de um hospital da rede privada (Hospital C).

A busca pelos protocolos clínicos ocorreu por meio de visitas às instituiçôes no mês de julho de 2015. Essa busca objetivou identificar os imunossupressores utilizados na terapia imunossupressora do TF e suas respectivas fases de indicação, que, atualmente, podem ser classificadas em indução, manutençáo e tratamento da rejeição; estas relativamente diferentes em termos de tempo, aos agentes e doses utilizadas. Para tal, utilizou-se um formulário simples confeccionado pelos autores.

Os fármacos foram entáo caracterizados em relaçáo a nome genérico, classe farmacológica, apresentação farmacológica, indicaçôes no transplante, mecanismo de ação, reações adversas e interações medicamentosas. Procedeu-se ainda com uma breve revisão sobre as 
classes farmacológicas dos imunossupressores identificados na busca aos protocolos. As informaçóes mais pertinentes foram sumarizadas em quadros com o intuito de facilitar a visualização e compreensão.

Para tal, revisou-se a literatura especializada na área da medicina e farmacologia nos meses de setembro e outubro de 2015, a partir das bases de dados eletrônicas Scientific Electronic Library Online (Scielo), Literatura Latino-Americana e do Caribe em Ciências da Saúde (Lilacs) e US National Library of Medicine/National Institutes of Health (MedLine/PubMed), empregando-se, de forma associada, os descritores na língua portuguesa "transplante de fígado" e "imunossupressores" e na língua inglesa "liver transplantation" e "immunosuppressive agents", terminologias catalogadas no Descritores em Ciências da Saúde (DECS) e no Medical Subject Headings (Mesh), respectivamente.

Foram utilizados como critérios de inclusão: artigos atualizados no recorte temporal de 2010 a 2015; na língua portuguesa, inglesa ou espanhola; disponíveis em texto completo online nas bases de dados definidas e que abordassem as características farmacológicas e clínicas dos imunossupressores. Para a caracterizaçáo da apresentação farmacológica, utilizou-se a Relação de Medicamentos Essenciais (Rename) ${ }^{9}$, caracterizando, assim, apenas as apresentações de circulação nacional.

A partir da caracterização e revisão dos imunossupressores, foi realizada uma revisão a respeito do manejo adequado desses fármacos pela equipe de enfermagem a partir de duas bases online de informaçôes médicas baseadas em evidências, o Micromedex ${ }^{10}$ e o UpToDate ${ }^{11}$, que fornecem um banco de dados sobre medicamentos, toxicologia, doenças e cuidados intensivos a profissionais de saúde, auxiliando na tomada de decisóes diagnósticas e de tratamento. Foram propostas ainda intervenções de enfermagem para as principais reações adversas aos imunossupressores.

\section{Resultados e discussões}

A partir da busca pelos protocolos clínicos de TF foi possível identificar os agentes imunossupressores utilizados pelas instituiçóes transplantadoras de acordo com suas fases de imunossupressão (Quadro 1).

Quadro 1: Distribuição das terapias imunossupressoras das instituições transplantadoras de fígado do estado do Ceará, Brasil, conforme fases de imunossupressão (jul., 2015).

\begin{tabular}{cccc}
\hline Fases da & Hospital A & Hospital B & Hospital C \\
imunossupressáo & Hidrocortisona & Metilprednisolona & Hidrocortisona \\
\hline Induçáo & Prednisona & & Prednisona \\
& Tacrolimo & Prednisona & Micofenolato de Sódio \\
Manutenção & Micofenolato de Sódio & Tacrolimo & Micofenolato de Mofetil \\
& Micofenolato de Mofetil & Micofenolato de Sódio & Ciclosporina \\
Tratamento da & Ciclosporina & Everolimo & Sirolimo \\
rejeição & Sirolimo & Não definido em protocolo & Metilprednisolona
\end{tabular}

A respeito das fases da terapia de imunossupressão, os protocolos sugerem que a terapia de induçáo deve iniciar-se ainda no intraoperatório e estender-se até 48 a 96 horas pós-transplante, quando então se inicia a terapia de manutenção. Já a terapia de tratamento das rejeiçốes sujeita-se ao grau de rejeição estabelecido no enxerto e ainda se a rejeição é definida como aguda ou crônica.

Os protocolos preconizam ainda que o esquema imunossupressor inicial de manutenção depende de algumas variáveis clínicas pré e pós-transplante que influenciam na decisão da terapia pela equipe transplantadora, a saber: presença de disfunçáo renal; Meld elevado pré-transplante; tratamento de infecçôes em curso; evolução das aminotransferases; efeitos adversos aos imunossupressores; diabetes de difícil manejo clínico e a doença hepática de base.

A depender das variáveis e da evolução clínica do paciente, os protocolos guiam a terapia de manutenção a ser utilizada, que pode variar desde a monoterapia, no qual se utiliza apenas um fármaco imunossupressor, até a politerapia, utilizando-se de dois a quatro medicamentos.

Portanto, os protocolos clínicos são elaborados a partir das evidências científicas e da própria experiência clínica da equipe transplantadora e guiam o manejo da terapia imunossupressora visando à adequada função do enxerto e minimizando os efeitos adversos associados ao uso desses medicamentos. 
Logo, baseado nos fármacos identificados nos protocolos clínicos pesquisados, este estudo procede-se com a discussáo desses medicamentos de acordo com a literatura pertinente.

\section{Agentes imunossupressores no transplante de fígado}

Nos transplantes de órgãos sólidos, os agentes imunossupressores são utilizados para a indução da imunossupressão na fase inicial do transplante, para a fase de manutenção da imunossupressão logo após e eventualmente para o tratamento de rejeição do enxerto ${ }^{1}$.

No cenário dos TF, os corticosteroides são os fármacos mais amplamente utilizados, já que compóe a terapia de base na imunossupressão de induçáo, de manutençáo e no tratamento das rejeiçóes ${ }^{6}$. Além dos corticosteroides, a terapia de manutenção atual inclui ainda os inibidores da calcineurina (ICN), os antiproliferativos e os inibidores da proteína alvo da rapamicina em mamíferos (mTOR)

No Quadro 2, os imunossupressores foram caracterizados de acordo com suas classificaçôes farmacológicas, assim como foram elencados as apresentaçóes farmacológicas disponíveis no Brasil de acordo com o Rename? .

Quadro 2: Caracterização dos fármacos imunossupressores quanto ao nome genérico, classificação farmacológica e apresentação farmacológica.

\begin{tabular}{|c|c|c|}
\hline Imunossupressor & Classificaçáo farmacológica & Apresentaçáo 9 \\
\hline Hidrocortisona & Corticosteroide & - Pó para solução injetável de $100 \mathrm{mg}$ e $500 \mathrm{mg}$ \\
\hline Metilprednisolona & Corticosteroide & - $\quad$ Solução injetável de $500 \mathrm{mg}$ \\
\hline Prednisona & Corticosteroide & - Comprimidos de $5 \mathrm{mg}$ e $20 \mathrm{mg}$ \\
\hline Tacrolimo & Inibidor da calcineurina & $\begin{array}{l}\text { - } \quad \text { Cápsulas de } 1 \mathrm{mg} \text { e } 5 \mathrm{mg} \\
\text { - } \quad \text { Soluçáo injetável de } 5 \mathrm{mg} / \mathrm{ml}\end{array}$ \\
\hline Ciclosporina & Inibidor da calcineurina & $\begin{array}{l}\text { - } \quad \text { Cápsulas de } 10 \mathrm{mg}, 25 \mathrm{mg}, 50 \mathrm{mg} \text { e } 100 \mathrm{mg} \\
\text { - } \quad \text { Solução injetável de } 50 \mathrm{mg} \\
\text { - } \quad \text { Solução oral de } 100 \mathrm{mg} / \mathrm{ml}\end{array}$ \\
\hline Micofenolato de Sódio & Antiproliferativo & - $\quad$ Comprimidos de $180 \mathrm{mg}$ e $360 \mathrm{mg}$ \\
\hline Micofenolato de Mofetil & Antiproliferativo & - $\quad$ Comprimidos de $500 \mathrm{mg}$ \\
\hline Sirolimo & Inibidor da mTOR & - $\quad$ Drágeas de $1 \mathrm{mg}$ e $2 \mathrm{mg}$ \\
\hline Everolimo & Inibidor da mTOR & - $\quad$ Comprimidos de $0,5 \mathrm{mg}, 0,75 \mathrm{mg}$ e $1 \mathrm{mg}$ \\
\hline
\end{tabular}

Legenda: mTOR: Proteína alvo da rapamicina em mamíferos.

No Quadro 3, procedeu-se com a caracterização dos imunossupressores de acordo com suas indicaçôes no TF, a síntese de seus mecanismos de ação e seus efeitos adversos mais comuns relacionados ao seu uso.
Já o Quadro 4 destaca as principais interaçóes medicamentosas que elevam ou reduzem os níveis séricos dos imunossupressores, de acordo com sua classificação farmacológica.

Quadro 3: Caracterização dos fármacos imunossupressores quanto à indicação no transplante, mecanismos de ação e efeitos adversos mais comuns.

\begin{tabular}{|c|c|c|c|}
\hline Imunossupressor & Indicaçóes no transplante & Mecanismos de açáo & Efeitos adversos \\
\hline Metilprednisolona & $\begin{array}{c}\text { Indução e manutenção da imunos- } \\
\text { supressão; tratamento das rejeiçóes } \\
\text { celulares agudas }\end{array}$ & $\begin{array}{l}\text { Bloqueiam a expressão } \\
\text { de citocinas das } \\
\text { células T e das células } \\
\text { apresentadoras de } \\
\text { antígeno }\end{array}$ & $\begin{array}{ll}\text { - } & \text { Hiperglicemia } \\
\text { - } & \text { Hipertensão } \\
\text { - } & \text { Obislipidemia } \\
\text { - } & \text { Hirsutismo } \\
\text { - } & \text { Retardo na cicatrização } \\
\text { - } & \text { Retardo no crescimento } \\
\text { - } & \text { Infecções oportunistas } \\
\text { - } & \text { Osteoporose } \\
\text { - } & \text { Supressão adrenal } \\
\text { - } & \text { Aparência cushingoide } \\
\text { - } & \text { Alteraçóes do humor } \\
\text { - } & \text { Distúrbios do sono }\end{array}$ \\
\hline
\end{tabular}


Quadro 3: Continuação.

\begin{tabular}{|c|c|c|c|}
\hline Imunossupressor & Indicaçóes no transplante & Mecanismos de ação & Efeitos adversos \\
\hline Ciclosporina & Manutenção da imunossupressão & $\begin{array}{l}\text { Liga-se à ciclofilina } \\
\text { formando comple- } \\
\text { xos que inibem a } \\
\text { calcineurina }\end{array}$ & $\begin{array}{ll}\text { - } & \text { Nefrotoxicidade } \\
\text { - } & \text { Hipertensão } \\
\text { - } & \text { Nislipidemia } \\
\text { - } & \text { Diabetes pós-transplante } \\
\text { - } & \text { Hipercalemia } \\
\text { - } & \text { Hipomagnesemia } \\
\text { - } & \text { Hirsutismo } \\
\text { - } & \text { Hiperplasia gengival } \\
\text { - } & \text { Infecçóes oportunistas } \\
\text { - } & \text { Malignidades } \\
\text { - } & \text { Semelhante ao tacrolimo, porém: } \\
\text { - } & \text { Mais problemas cardiovasculares } \\
\text { - } & \text { Mais hirsutismo e hiperplasia gengival } \\
\text { - } & \text { Menos diabetes pós-transplante } \\
\text { - } & \text { Menos neurotoxicidade }\end{array}$ \\
\hline $\begin{array}{l}\text { Micofenolato de } \\
\text { Sódio } \\
\text { Micofenolato de } \\
\text { Mofetil }\end{array}$ & $\begin{array}{l}\text { Manutenção da imunossupressão; trata- } \\
\text { mento das rejeiçôes }\end{array}$ & Inibem a IMPDH & $\begin{array}{ll}\text { - } & \text { Náuseas e vômitos } \\
\text { - } & \text { Diarreia } \\
\text { - } & \text { Leucopenia } \\
\text { - } & \text { Trombocitopenia } \\
\text { Anemia }\end{array}$ \\
\hline Everolimo & $\begin{array}{c}\text { Manutenção da imunossupressão; trata- } \\
\text { mento das rejeiçôes; interesses especiais } \\
\text { para uso em doenças malignas }\end{array}$ & $\begin{array}{l}\text { Liga-se à FKBP12 } \\
\text { formando complexos } \\
\text { que inibem a mTOR }\end{array}$ & $\begin{array}{ll}\text { - } & \text { Retardo na cicatrização } \\
\text { - } & \text { Hipertensão } \\
\text { - } & \text { Edema } \\
\text { - } & \text { Nislipidemia } \\
\text { - } & \text { Diarreas e vômitos } \\
\text { - } & \text { Anemia } \\
\text { - } & \text { Trombocitopenia } \\
\text { - } & \text { Cefaleias } \\
\text { - } & \text { Doença pulmonar intersticial } \\
\text { - } & \text { Trombose da artéria hepática } \\
\text { - } & \text { Aftas } \\
\text { - } & \text { Acne } \\
\text { - } & \text { Infecçóes oportunistas } \\
\text { - } & \text { Malignidades } \\
\end{array}$ \\
\hline
\end{tabular}

Legenda: FKBP12: Proteína de ligação do FK506. IMPDH: Inosina monofosfato desidrogenase. mTOR: Proteína alvo da rapamicina em mamíferos.

Quadro 4: Principais interações medicamentosas que alteram os níveis séricos dos imunossupressores.

\begin{tabular}{|c|c|c|}
\hline Imunossupressor & Elevam os níveis séricos & Reduzem os níveis séricos \\
\hline Corticosteroides & $\begin{array}{ll}\text { - } & \text { Itraconazol; } \\
\text { - } & \text { Fluconazol; } \\
\text { - } & \text { Ritonavir; } \\
\text { Lopinavir. }\end{array}$ & $\begin{array}{l}\text { - } \quad \text { Barbitúricos (p. ex. fenobarbital, secobarbital, } \\
\text { pentobarbital); } \\
\text { - } \quad \text { Fenitoína; } \\
\text { - } \quad \text { Primidona; } \\
\text { - } \quad \text { Rifampicina; } \\
\text { - Rifapentina. }\end{array}$ \\
\hline
\end{tabular}


Quadro 4: Continuação

\begin{tabular}{|c|c|c|}
\hline Imunossupressor & Elevam os níveis séricos & Reduzem os níveis séricos \\
\hline $\begin{array}{l}\text { Inibidores da } \\
\text { calcineurina }\end{array}$ & $\begin{array}{l}\text { - Antibióticos macrolídeos (p. ex. claritromi- } \\
\text { - } \quad \text { Antina, eritromicina, azitromicina); } \\
\text { cetoconazol, itraconazol, voriconazol); } \\
\text { - } \quad \text { Bloqueadores dos canais de cálcio (p. ex. } \\
\text { nifedipina, amlodipina); } \\
\text { - Quinolonas (p. ex. ciprofloxacino, } \\
\text { levofloxacino); } \\
\text { - Inibidores de protease (p. ex. lopinavir, } \\
\text { - } \quad \text { Antianavir, saquinavir, veruprevir); } \\
\text { - } \quad \text { Propafenona); } \\
\text { - Inibinéticos (p. ex. metoclopramida); } \\
\text { lansoprazol, omeprazol, cimetidina; exceto } \\
\text { o pantoprazol); } \\
\text { - Alopurinol; } \\
\text { - } \quad \text { fluoxetina; } \\
\text { Álcool; } \\
\text { Toranja*. }\end{array}$ & 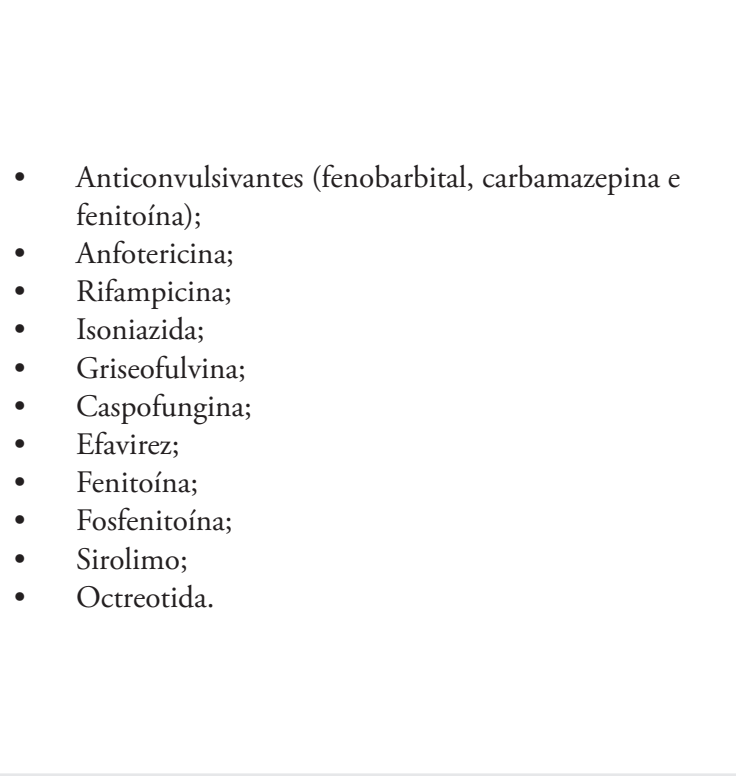 \\
\hline Antiproliferativos & $\begin{array}{ll}\text { - } & \text { Aciclovir; } \\
\text { - } & \text { Ganciclovir; } \\
\text { - } & \text { Valaciclovir; } \\
\text { - } & \text { Furicilatos (p. ex. ácido acetilsalicílico); } \\
\text { - } & \text { Probenecida. }\end{array}$ & $\begin{array}{l}\text { - Corticosteroides; } \\
\text { - Ciclosporina; } \\
\text { - Quinolonas (p. ex. ciprofloxacino, levofloxacino); } \\
\text { - } \quad \text { Metronidazol; } \\
\text { - } \quad \text { Inibamicina; } \\
\quad \text { pantopres da bomba de prótons (p. ex. omeprazol, } \\
\text { - Sequestradores de ácidos biliares (p. ex. colestiramina); } \\
\text { - Sevelamer; } \\
\text { - Antiácidos. }\end{array}$ \\
\hline Inibidores da mTOR & $\begin{array}{l}\text { Antibióticos macrolídeos (p. ex. } \\
\text { claritromicina, eritromicina); } \\
\text { Antifúngicos azólicos (p. ex. fluconazol, } \\
\text { cetoconazol, itraconazol, voriconazol); } \\
\text { Bloqueadores dos canais de cálcio (p. ex. } \\
\text { nifedipina, amlodipina); } \\
\text { - Inibidores de protease (p. ex. lopinavir, } \\
\text { ritonavir, saquinavir, veruprevir); } \\
\text { - Ciclosporina; } \\
\text { - Procinéticos (p. ex. metoclopramida); } \\
\text { - Toranja*. }\end{array}$ & $\begin{array}{ll}\text { - } & \text { Fenitoína; } \\
\text { - } & \text { Fosfenitoína; } \\
\text { - } & \text { Efavirenz. }\end{array}$ \\
\hline
\end{tabular}

*Também conhecida como grapefruit, é uma fruta cítrica híbrida resultante do cruzamento do pomelo com a laranja.

\section{Corticosteroides}

Os corticosteroides têm sido um dos pilares para a indução da imunossupressão desde os primeiros casos bem sucedidos de transplantes de órgãos sólidos. Atualmente, poucos centros elaboram diretrizes de imunossupressão evitando o uso completo dos corticosteroides ${ }^{1,6}$.

Devido à sua ampla gama de efeitos imunossupressores, os corticosteroides compóem a maioria dos protocolos de imunossupressáo no TF, sendo utilizados tanto nas terapias de indução e manutenção como também no tratamento de episódios de rejeição aguda, perfazendo no último a primeira linha de tratamento ${ }^{12,13,14}$.

Durante a induçáo, os corticosteroides são administrados em altas doses por via endovenosa, sendo rapidamente reduzidos a doses relativamente baixas na primeira semana, mantendo-se depois em regime de manutenção por via oral por pelo menos três a seis meses 
pós-transplante, embora alguns centros mantenham os pacientes em doses mínimas por tempo indeterminado. Comumente associa-se o corticosteroide a um ICN e/ ou a um antiproliferativo para compor o regime de manutenção da imunossupressão ${ }^{1}$.

Com atividade anti-inflamatória e imunossupressora, os corticosteroides agem através do bloqueio dos derivados de células $\mathrm{T}$ e a expressão de citocinas em células apresentadoras de antígeno, resultando em leucocitose neutrofílica, acompanhada por reduções dramáticas nos eosinófilos, monócitos e linfócitos circulantes. As células $\mathrm{T}$ circulantes diminuem rapidamente devido a uma combinação de efeitos, incluindo a redistribuição, a inibição de citocinas pró-inflamatórias e a indução de apoptose. As células B são menos afetadas e a produção de anticorpos é, em grande parte, preservada ${ }^{12,14}$.

Todas as células possuem receptores para corticosteroides, tornando comum o surgimento de várias reaçóes adversas, sendo, portanto, evitados em doses elevadas em longo prazo por alguns centros transplantadores por causar morbidade significativa em curto e em longo prazo entre os receptores de fígado ${ }^{6,14}$. Os principais efeitos adversos relacionados aos corticosteroides são as alterações metabólicas (Quadro 3).

\section{Inibidores da calcineurina}

A descoberta dos ICN, inicialmente a ciclosporina e posteriormente o tacrolimo, revolucionou os regimes imunossupressores de transplantes de órgãos sólidos, melhorando significativamente as taxas de sobrevida do enxerto e reduzindo as taxas de rejeições agudas ${ }^{12,15}$.

A partir de então, os ICN foram incluídos como as principais drogas imunossupressoras dos protocolos de imunossupressão de TF por conta de seus excelentes efeitos protetores de órgãos ${ }^{1}$. Os pacientes transplantados geralmente permanecem em uso dos ICN pelo resto da vida útil do enxerto, mesmo se todos os outros imunossupressores forem retirados ${ }^{14}$.

Nos transplantes em geral, a escolha entre a ciclosporina e o tacrolimo varia entre os centros transplantadores ao redor do mundo ${ }^{6}$, no entanto, vários estudos ${ }^{1,12,13,14}$ favorecem o uso do tacrolimo por apresentar uma melhor taxa de sobrevida do enxerto, menor incidência de rejeição celular aguda e menor toxicidade renal em comparaçáo com a ciclosporina nos primeiros dois anos pós-transplante. No TF, a ciclosporina não é o ICN de escolha, entretanto, em casos especiais, pode haver a necessidade de substituir o tacrolimo pela ciclosporina ${ }^{1}$.

Quanto ao mecanismo de ação dos ICN, a ciclosporina se liga a ciclofilina, enquanto o tacrolimo liga-se à proteína de ligação FK12 (FKBP12). Ambas as ligaçôes formam complexos que resultam na inibição da calcineurina, uma fosfatase presente em células $\mathrm{T}$, que inibe a ativação do fator nuclear de células $T$ ativadas (NFAT), levando a uma regulaçáo negativa de interleucinas 2, 3 e 4 (IL-2, IL-3 e IL-4); fator de necrose tumoral alfa (TNF-alfa); interferon gama (IFN-gama); dentre outros, interrompendo, assim, o crescimento e diferenciação de células $T^{1,5,12}$.

Vale ressaltar que a potência de ligaçáo do tacrolimo é de 10 a 100 vezes mais forte quando comparado à ciclosporina, inibindo a calcineurina com maior eficácia, demandando, assim, doses menores de $\mathrm{ICN}^{5,14}$.

As reaçóes adversas são mais prováveis de ocorrer quando as concentrações do fármaco estão em níveis supraterapêuticos, porém, reações em níveis terapêuticos podem ocorrer ${ }^{14}$. A hipertensão arterial e a nefrotoxicidade aguda e crônica são as reações adversas mais comuns da terapia com ICN, e a última pode variar desde pequenas alteraçôes nos valores de ureia e creatinina - reversíveis com a redução da dose da droga -, a casos mais graves como alteraçóes histológicas evidentes na biopsia renal. Outra reação comum é a neurotoxicidade, apresentando-se como quadros de cefaleia, tremores, encefalopatia, convulsóes, delírios e coma. A hiperglicemia ou diabetes pós-transplante pode ser reversível ou necessitar de tratamento com insulina. Alguns desses efeitos podem, ainda, diminuir a adesão ao tratamento ${ }^{1,14,16}$.

Apesar de ambos os ICN possuírem reaçóes adversas semelhantes, o tacrolimo tem uma menor incidência de hiperlipidemia, hipertensão e problemas estéticos, como hirsutismo e hiperplasia gengival, mas é mais provável do que a ciclosporina para induzir diabetes pós-transplante e neurotoxicidade ${ }^{5,12,14}$.

Dessa forma, os níveis séricos dos ICN devem ser monitorados para garantir um equilíbrio entre o nível de imunossupressáo e suas reaçóes adversas associadas. Os níveis séricos de tacrolimo e de ciclosporina (ciclosporinemia) devem ser colhidos para análise no período matinal antes da ingestáo da primeira dose do dia, ou seja, em C0 (C zero), traduzindo assim, os níveis da droga nas últimas doze horas ${ }^{16}$. Para a ciclosporina, alguns centros transplantadores adotam outra forma de monitorização: o nível sérico de pico duas horas após a ingestão da última dose, ou seja, em C2 (C dois). Os valores ideais dos níveis séricos dos ICN podem variar de acordo com os centros transplantadores e/ou com o tempo pós-transplante, como também a associação destes com outros imunossupressores ${ }^{1,14}$.

Outra questão importante ao utilizar os ICN é a gama de interaçóes medicamentosas que podem elevar ou diminuir seus níveis séricos (Quadro 4). Ambos o tacrolimo e a ciclosporina possuem interaçóes semelhantes dado seu metabolismo hepático comum por meio do sistema enzimático citocromo $\mathrm{P} 450^{11}$. 


\section{Antiproliferativos}

Nessa classe farmacológica, dois exemplos bem conhecidos são a azatioprina e o micofenolato, utilizados na fase de manutenção da imunossupressáo. $\mathrm{O}$ micofenolato é atualmente utilizado com mais frequência do que a azatioprina, substituindo-o após cinco décadas de êxito como agente imunossupressor antiproliferativo na área do transplante de órgáos sólidos ${ }^{5,12,14}$.

Esse fenômeno se explica pelo fato de que o micofenolato é um agente antiproliferativo mais seletivo do que a azatioprina, apresentando menor risco de hepatotoxicidade e não estando associado a malignidades ${ }^{12}$. Provavelmente devido a essa circunstância, a azatioprina não foi citada como droga integrante da terapia imunossupressora do TF nos protocolos clínicos pesquisados neste estudo. Em consequência, essa droga não será abordada nesta discussão.

O micofenolato é amplamente utilizado em combinação com os ICN em pacientes que necessitam de terapia nefroprotetora, graças ao seu baixo potencial nefrotóxico, o que possibilita reduzir os níveis de ICN. Essa combinação torna-se útil ainda quando se deseja retirar o corticosteroide do esquema imunossupressor de manutenção ${ }^{1,13}$.

O micofenolato é um pró-fármaco que é rapidamente metabolizado no seu metabólito ativo, o ácido micofenólico (MPA). O micofenolato apresenta como principais vantagens em relação ao MPA: maior biodisponibilidade, eficácia e tolerabilidade. O fígado é o principal local de metabolizaçáo do micofenolato e grande parte da dose administrada é eliminada pela via renal $^{12,16}$.

Atualmente, o micofenolato encontra-se disponível em duas formulaçôes, o micofenolato de mofetil (MMF) e o mais recentemente desenvolvido, o micofenolato de sódio (MPS). O MPS possui um revestimento gastrorresistente que permite uma liberação lenta do micofenolato, melhorando a tolerabilidade gastrintestinal e reduzindo os efeitos adversos gastrintestinais ${ }^{5,12,14}$. Vale ressaltar que $360 \mathrm{mg}$ (um comprimido) do MPS corresponde a $500 \mathrm{mg}$ (um comprimido) do $\mathrm{MMF}^{16}$.

Quando metabolizado em seu composto ativo - o MPA -, o micofenolato inibe a inosina monofosfato desidrogenase (IMPDH), uma enzima necessária para a síntese de guanosina nos linfócitos, limitando a síntese de DNA e resultando em atividade antiproliferativa de células $\mathrm{B} \mathrm{e} \mathrm{T}^{6,14}$. Ele ainda pode inibir a quimiotaxia de monócitos, a expressão de moléculas de adesão sobre os linfócitos, induzir apoptose em linfócitos ativados e diminuir o recrutamento de células inflamatórias ${ }^{1,5}$.

As principais reaçôes adversas relacionadas a esse imunossupressor são hematológicas e gastrintestinais. A mielotoxicidade, com consequente leucopenia, é geralmente dose-dependente e responde bem à redução da dose. Náuseas, vômitos, desconforto abdominal e diarreia são queixas comuns em pacientes em uso da droga ${ }^{1,5}$. As mulheres em idade fértil devem ser aconselhadas sobre a prevenção e o planeamento da gravidez, devido ao risco de aborto no primeiro trimestre e malformaçóes congênitas com o uso do micofenolato ${ }^{14}$. Outros efeitos menos comuns estão descritos no Quadro 3.

A biodisponibilidade do micofenolato é alta e a monitorização dos níveis séricos da droga não é geralmente recomendada, no entanto, o ajuste da dose é realizado de acordo com a avaliaçáo da mielotoxicidade por meio da análise periódica do hemograma completo ${ }^{1,14}$. As drogas que interagem com o micofenolato alterando seus níveis séricos estão elencadas no Quadro 4.

\section{Inibidores da mTOR}

Outra classe de potentes imunossupressores compreende os inibidores da proteína alvo da rapamicina em mamíferos, ou mammalian target of rapamycin (mTOR), uma proteína quinase que tem ação sobre amplos aspectos do crescimento celular, da transcrição e da síntese de proteínas 5 . Há dois inibidores da mTOR disponíveis aos pacientes submetidos ao TF, o sirolimo e o everolimo. Em modelos animais, essas drogas têm mostrado propriedades imunossupressoras e antitumorais, inclusive contra o $\mathrm{CHC}^{13}$.

O seu primeiro representante, o sirolimo, trata-se de um antibiótico macrolídeo estruturalmente semelhante ao tacrolimo, ambos ligam-se à FKBP12, porém o sirolimo inibe a $\mathrm{mTOR}$ em vez de inibir a calcineurina. Entretanto, apesar de se ligarem ao mesmo receptor celular, atuam sinergicamente e não competem entre si, possibilitando terapias com associação de ICN e inibidores da mTOR ${ }^{1}$.

O everolimo mostrou resultados promissores semelhantes em relação às taxas de rejeição e aos efeitos benéficos significativos na função renal quando combinada com baixas doses de ICN. No entanto, quando utilizado como monoterapia no regime de imunossupressão, mostrou índices maiores na taxa de rejeiçáo. Por isso, o uso combinado com ICN é sugerido de modo a diminuir o risco de rejeição ${ }^{1}$.

Outra utilidade clínica dos inibidores da mTOR no TF é baseada em seu efeito antitumoral. Muitos centros transplantadores frequentemente os utilizam em sua terapia quando existem fatores de risco para doença maligna após o TF, ou mesmo quando um tumor já foi diagnosticado ${ }^{12,13}$. Ademais, nos TF por $\mathrm{CHC}$, a imunossupressão baseada no sirolimo foi associada a menores taxas de reincidência do tumor, maior sobrevida global e livre de recidiva, e menor mortalidade relacionada à recidiva quando comparado aos $\mathrm{ICN}^{1}$. 
Com relação ao seu mecanismo de ação, os inibidores da mTOR ligam-se à FKBP12 formando complexos que inibem a mTOR e consequentemente seu papel-chave na regulação de vários processos na célula, afetando seu metabolismo, divisáo celular, crescimento e proliferação, principalmente de células $\mathrm{T}^{12,13,14}$. As indicaçôes oncológicas dos inibidores da mTOR devem-se às suas propriedades antiproliferativas ${ }^{12}$.

Os efeitos adversos comuns relacionados a esses imunossupressores são o edema, a trombocitopenia, a hiperlipidemia, lesóes de pele e as úlceras orais ${ }^{1,5,12}$. Outros efeitos adversos relevantes são a sua capacidade de reduzir a cicatrização da ferida cirúrgica e o elevado risco de trombose da artéria hepática, contribuindo para mais complicaçôes quando introduzidos precocemente após o transplante de órgãos sólidos. Portanto, é preferível que os inibidores da mTOR sejam iniciados pelo menos um mês após o transplante ${ }^{1,14}$.

Por serem metabolizados pela via citocromo P450, assim como os ICN, os inibidores da mTOR podem ter suas concentraçóes séricas alteradas com o uso concomitante de algumas drogas ${ }^{14}$ (Quadro 4).

\section{Manejo dos agentes imunossupressores pela equipe de enfermagem}

A administração dos imunossupressores é uma das importantes funçóes da equipe de enfermagem envolvida na assistência ao paciente transplantado de fígado. Logo, é de suma importância que a equipe conheça as indicaçôes, vias de administração, monitorização, os mecanismos de ação, riscos e benefícios, efeitos adversos e cuidados necessários quanto ao uso dessa terapêutica.

Com base nesses conhecimentos, a equipe poderá não apenas se apropriar da administração dos fármacos de forma segura e eficaz, mas também realizar de forma competente seu papel de educador, garantindo uma terapia medicamentosa com riscos mínimos, tanto no ambiente hospitalar como no domicílio do paciente.

A princípio, um ponto fundamental no manejo de drogas imunossupressoras é a utilização de medidas de precauçóes padrão pelos profissionais de saúde. Isso se deve ao fato de que essas drogas possuem alto risco oncogênico e teratogênico, portanto, sempre que for necessário manipular cápsulas (por exemplo, abrir cápsulas ou preparar suspensóes orais) ou infusóes, recomenda-se usar dupla luva, avental, máscara e, se possível, preparar em uma capela de fluxo laminar. Devido ao risco reconhecido de teratogenicidade do micofenolato, recomenda-se que seus comprimidos nunca devam ser macerados ou cortados ${ }^{11}$.

Não obstante, os pacientes transplantados são a população mais vulnerável aos riscos relacionados ao uso dos imunossupressores. Essas drogas, com exceção dos corticosteroides, predispóem, além de suas reaçôes adversas próprias, o paciente ao risco de desenvolver malignidades, principalmente o linfoma e o câncer de pele, e maior suscetibilidade às infecçóes ${ }^{11}$.

Outra questão importante é a interação dos imunossupressores com os alimentos, pois a absorção dessas drogas é ótima quando tomadas na ausência de alimentos. Recomenda-se entáo que sejam administrados pelo menos uma hora antes ou duas horas após as refeiçôes, evitando-se assim, a competitividade de absorção e consequente redução dos níveis séricos das drogas ${ }^{10,11}$. No entanto, a prednisona é aconselhável tomar junto das refeiçóes ${ }^{10}$.

Além dessas recomendaçóes gerais, cada imunossupressor apresenta ainda suas particularidades relacionadas à sua administração, principalmente os $\mathrm{ICN}$, por possuírem apresentaçốes endovenosas. Tais particularidades estão descritas mais detalhadamente no Quadro 5.

Quadro 5: Principais características relacionadas à administração dos imunossupressores e seus parâmetros de monitorização clínica.

\begin{tabular}{|c|c|}
\hline Imunossupressor & Administração \\
\hline Hidrocortisona & IV: Pode ser diluído até uma concentração de $1 \mathrm{mg} / \mathrm{ml}$ em SF $0.9 \%$ ou SG 5\%. \\
\hline Metilprednisolona & IV: A solução reconstituída com o diluente próprio da embalagem é estável por 48 horas. \\
\hline Prednisona & Oral: Tomar preferencialmente junto a uma refeição. \\
\hline Tacrolimo & $\begin{array}{l}\text { Oral: Administrar uma hora antes ou duas horas após as refeiçōes. Aprazar a maior dose para o } \\
\text { período da manhã, caso as duas doses diárias difiram. IV: Diluir em SF 0,9\% ou SG 5\%; deve } \\
\text { ser administrado em bomba de infusão contínua e em equipo livre de PVC, monitorando os } \\
\text { primeiros trinta minutos de infusão (risco de anafilaxia); não administrar juntamente com solu- } \\
\text { çóes muito alcalinas. Incompatibilidades ao mesmo lúmen: Aciclovir, Ganciclovir e Fenitoína. }\end{array}$ \\
\hline Ciclosporina & $\begin{array}{l}\text { Oral: Administrar uma hora antes ou duas horas após as refeiçōes, sempre nos mesmos horários } \\
\text { diariamente. Soluçáo oral: Pode ser diluída em suco de laranja, maçãa, leite ou achocolatado; } \\
\text { misturar em recipiente de vidro. IV: Diluir em SF 0,9\% ou SG 5\%; deve ser administrado len- } \\
\text { tamente em bomba de infusão contínua, monitorando os primeiros trinta minutos de infusão } \\
\text { (risco de anafilaxia); descartar soluçáo após } 24 \text { horas. Incompatibilidades ao mesmo lúmen: } \\
\text { Aciclovir, Anfotericina B Lipossomal, Drotregogina Alfa e Pantoprazol. }\end{array}$ \\
\hline
\end{tabular}

Monitorizaçáo
clínica
Pressão arte-
rial, glicemia e
lipidograma.
Níveis séricos do
imunossupressor,
funçáo renal,
funçáo hepática,
eletrólitos séricos
(cálcio, magnésio,
potássio), pressão
arterial, glicemia,
lipidograma, rea-
çôes de hipersen-
sibilidade (IV) e
toxicidade ao SNC.

continua... 
Quadro 5: Continuação

\begin{tabular}{|c|c|c|}
\hline Imunossupressor & Administraçáo & $\begin{array}{l}\text { Monitorizaçáo } \\
\text { clínica }\end{array}$ \\
\hline $\begin{array}{l}\text { Micofenolato de } \\
\text { Sódio }\end{array}$ & $\begin{array}{l}\text { Oral: Pode ser administrado em jejum ou com alimentos, porém, deve-se seguir sempre a mes- } \\
\text { ma forma de administração. }\end{array}$ & \multirow{2}{*}{$\begin{array}{l}\text { Hemograma com- } \\
\text { pleto e sintomas } \\
\text { abdominais. }\end{array}$} \\
\hline $\begin{array}{l}\text { Micofenolato de } \\
\text { Mofetil }\end{array}$ & $\begin{array}{l}\text { Oral: Pode ser administrado em jejum ou com alimentos, porém, deve-se seguir sempre a mes- } \\
\text { ma forma de administração. Não administrar simultaneamente com antiácidos. }\end{array}$ & \\
\hline Sirolimo & $\begin{array}{l}\text { Oral: Pode ser administrado em jejum ou com alimentos, porém, deve-se seguir sempre a mes- } \\
\text { ma forma de administração. Não esmagar, dividir ou mastigar. Evitar tomar no mesmo horário } \\
\text { da Ciclosporina, tomar pelo menos quatro horas após. }\end{array}$ & $\begin{array}{l}\text { Hemograma com- } \\
\text { pleto, níveis séricos }\end{array}$ \\
\hline Everolimo & $\begin{array}{l}\text { Oral: Pode ser administrado em jejum ou com alimentos, porém, deve-se seguir sempre a mes- } \\
\text { ma forma de administração. Náo esmagar, dividir ou mastigar. Administrar no mesmo horário } \\
\text { dos ICN. }\end{array}$ & $\begin{array}{l}\text { do imunossupres- } \\
\text { sor e lipidograma. }\end{array}$ \\
\hline
\end{tabular}

Legenda: IV: Intravenosa. SF 0,9\%: Soro fisiológico a 0,9\%. SG 5\%: Soro glicosado a 5\%. PVC: Policloreto de polivinila. SNC: Sistema nervoso central. ICN: Inibidores da calcineurina.

Ainda no Quadro 5, destacam-se os principais parâmetros de monitorização clínica da terapia imunossupressora. Tais parâmetros incluem desde a avaliação dos sinais vitais, da avaliação física e dos exames laboratoriais até a avaliação dos níveis séricos dos imunossupressores, o que, em conjunto, vão conduzir ao equilíbrio entre controle do risco de rejeição do enxerto e do surgimento dos eventos adversos da terapia.

Quanto à abordagem sobre eventos adversos da terapia medicamentosa, surge a necessidade de diferenciar seus dois componentes fundamentais: as reaçóes adversas a medicamentos (RAM) e os erros de medicação. O primeiro diz respeito ao risco inerente diante da utilização adequada dos medicamentos, portanto, inevitáveis. Já os erros de medicação são eventos passíveis de prevenção, decorrentes do uso inadequado, ou não; portanto, possivelmente relacionado com falhas nos procedimentos ${ }^{17}$.

Nesse aspecto, a equipe de enfermagem pode e deve atuar nesses dois componentes. Nas RAM, por ser inevitável, o enfermeiro atua de forma intervencionista, identificando, planejando e intervindo sobre as reações apresentadas, seja de forma direta, em ambiente hospitalar, seja de forma indireta, através de orientaçóes, no ambiente domiciliar do paciente transplantado.
Já em relação aos erros de medicação, pode-se atuar de forma intervencionista e principalmente preventiva, garantindo uma assistência livre de imprudência, imperícia ou negligência por meio do correto aprazamento dos imunossupressores e do cumprimento dos "nove certos" da administração de medicamentos, assim como o empoderamento do paciente para o autocuidado quando em ambiente domiciliar, para que ele, longe da supervisão e cuidados da equipe, possa garantir sua própria segurança na tomada dos imunossupressores.

Esses eventos podem ainda ser muito perturbadores e influenciar na adesão medicamentosa e na qualidade de vida dos receptores de TF. Assim, a avaliação cuidadosa e o manejo dos sintomas são cruciais para a formulação de estratégias que podem ajudar a reduzir os sintomas, promover a adesão medicamentosa e fornecer, em longo prazo, uma melhor qualidade de vida após o transplante?

Com esse intuito, propôs-se neste estudo intervenções de enfermagem a algumas das principais reaçôes adversas relacionadas aos imunossupressores, como exposto no Quadro 6. Tais intervençóes referem-se não apenas às açóes diretas ao paciente internado, mas também orientaçóes a serem seguidas em ambiente domiciliar, durante a alta do paciente e nas consultas ambulatoriais. 
Quadro 6: Proposta de intervenções de enfermagem às reações adversas mais comuns aos imunossupressores.

\begin{tabular}{|c|c|}
\hline $\begin{array}{c}\text { Reaçóes } \\
\text { adversas mais } \\
\text { comuns }\end{array}$ & Intervençóes de enfermagem \\
\hline Hipertensão & $\begin{array}{l}\text { - } \quad \text { Monitorar e registrar padrões hemodinâmicos; } \\
\text { - } \quad \text { Ronitorar e registrar curva pressórica; } \\
\text { - } \quad \text { Observar e registar características de edema periférico; } \\
\text { - } \quad \text { Administrar agentes hipotensores, CPM; } \\
\text { - } \quad \text { Atentar para sinais de confusão mental, irritabilidade, desorientação, cefaleia, náuseas e vômito; } \\
\text { - Oferecer dieta leve, fracionada, hipossódica e hipolipídica, orientando sobre os benefícios; } \\
\text { Orientar o paciente sobre verificar sua pressão arterial diariamente. }\end{array}$ \\
\hline Hiperglicemia & $\begin{array}{l}\text { - } \quad \text { Administrar agentes hipoglicemiantes, CPM; } \\
\text { - } \quad \text { Onitorar e registar curva glicêmica; } \\
\text { - } \quad \text { Encorajar o paciente a monitorar seus níveis glicêmicos; } \\
\text { - } \quad \text { Encorajar a prática de exercícios físicos; } \\
\text { - Oferecer dieta fracionada, hipoglicídica e hipolipídica, orientando sobre os benefícios. }\end{array}$ \\
\hline Nefrotoxicidade & $\begin{array}{l}\text { - } \quad \text { Monitorar e registrar peso diariamente; } \\
\text { - } \quad \text { Realizar balanço hídrico; } \\
\text { - } \quad \text { Observitorar funçáo renal; } \\
\text { - } \quad \text { Monitorar e registrar naríveis dos imunossupressores; } \\
\text { - } \quad \text { Regininistrar diuréticos, CPM; } \\
\text { - } \quad \text { Preparar o paciente para diálise, QN. }\end{array}$ \\
\hline Dislipidemia & $\begin{array}{l}\text { - } \quad \text { Administrar agentes hipolipemiantes, CPM; } \\
\text { - } \quad \text { Oonitorar perfil lipídico; } \\
\text { - } \quad \text { Orientar para prática de exercícios físicos. }\end{array}$ \\
\hline Neurotoxicidade & $\begin{array}{l}\text { - Monitorar e registrar níveis dos imunossupressores; } \\
\text { - } \quad \text { Monitorar e auxiliar a capacidade de autocuidado, QN; } \\
\text { - } \quad \text { Encamitorar e registrar orientação no tempo, espaço e pessoa; } \\
\text { - } \quad \text { Proporcionar um ambiente seguro a nível hospitalar e domiciliar; } \\
\text { - } \quad \text { Solicitar e explicar a importância de um acompanhante durante a terapia; } \\
\text { - Registrar características e intensidade da dor, quando presente. }\end{array}$ \\
\hline Diarreia & 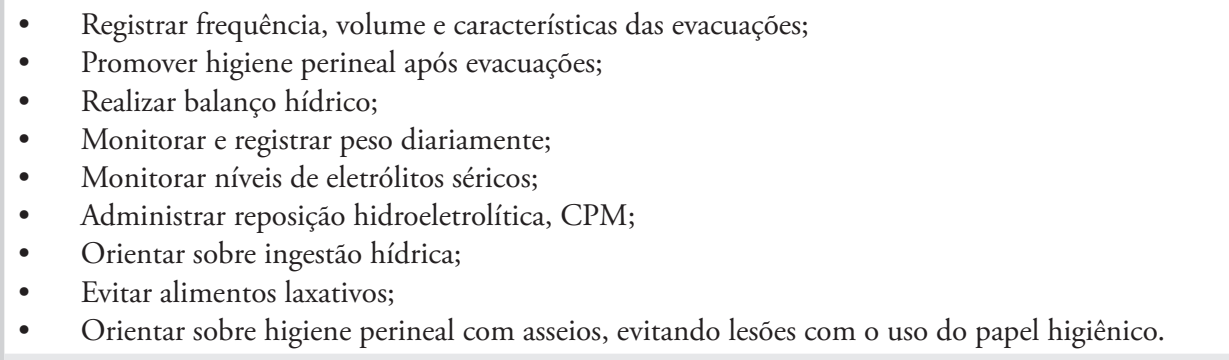 \\
\hline Anemia & $\begin{array}{l}\text { - Monitorar resultados do hemograma; } \\
\text { - } \quad \text { Monitorar e registrar sinais de palidez, fraqueza, tontura e dispneia; } \\
\text { - } \quad \text { Instalar cateter de oxigênio, QN; } \\
\text { - } \quad \text { Administrar hemocomponentes, CPM; } \\
\text { - Orientar sobre repouso/sono adequados; } \\
\text { - Orientar sobre dieta rica em líquidos, ferro e ácido fólico. }\end{array}$ \\
\hline
\end{tabular}


Quadro 6: Continuação.

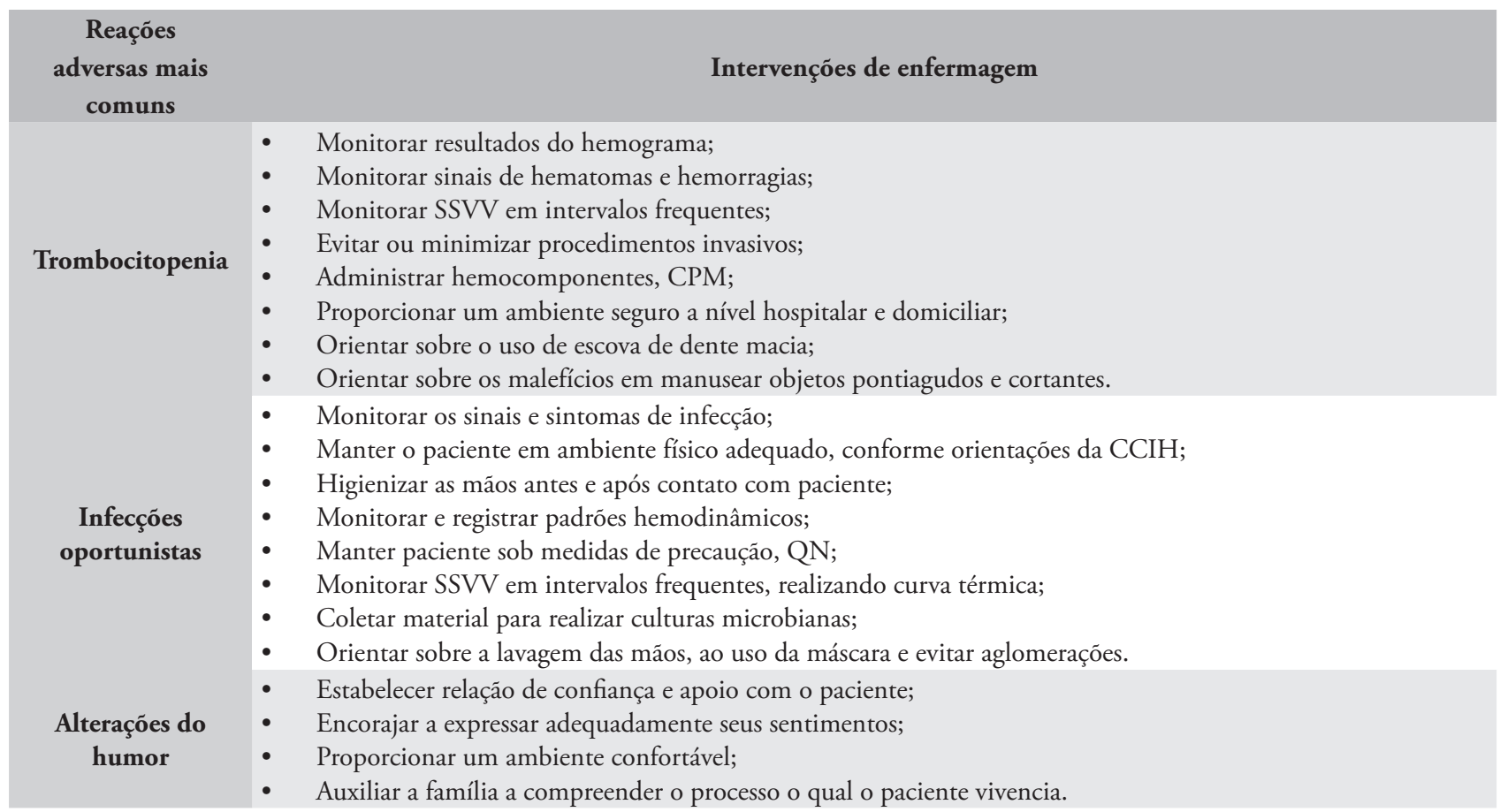

Legenda: CPM: Conforme prescrição médica. CCIH: Comissão de controle de infecção hospitalar. QN: Quando necessário. SSVV: Sinais vitais.

Outro aspecto relevante que merece atenção ao se administrar os imunossupressores são as interaçôes medicamentosas. Uma interação medicamentosa é considerada um evento clínico em que os efeitos de um fármaco são alterados pela presença de outro fármaco, fitoterápico, alimento, bebida ou algum agente químico ambiental. Quando administrados concomitantemente a um paciente, podem agir de forma independente ou interagir entre si, com aumento ou diminuiçáo de efeito terapêutico ou tóxico de um e/ou de outro ${ }^{18}$.

E quase impossível lembrar-se de todas as interaçóes medicamentosas conhecidas, mesmo dentro de uma classe farmacológica específica, como os imunossupressores. Logo, as principais interaçóes que elevam ou reduzem os níveis séricos dos imunossupressores estáo listadas no Quadro 4, como já visto anteriormente.

Vale ressaltar que as interaçóes medicamentosas envolvem também o uso de vacinas, sejam elas vivas ou inativadas. Em relação às inativadas, os imunossupressores podem reduzir sua eficácia. Orienta-se que todas as vacinas, desde que indicadas pela idade, sejam concluídas pelo menos duas semanas antes de iniciar a terapia imunossupressora. Se vacinados durante o uso dos imunossupressores, devem-se revacinar pelo menos três meses após a interrupção da terapia, caso necessário ${ }^{11}$.

No tocante às vacinas vivas, os imunossupressores podem reduzir sua eficácia e também aumentar os seus efeitos adversos e tóxicos, bem como o risco de infecção pela própria vacina ${ }^{10,11}$.

Uma orientação importante que deve ser compreendida, tanto pelos pacientes transplantados como pelos profissionais de saúde da atenção básica, é que pacientes em uso crônico de imunossupressores não devem ser imunizados com vacinas vivas durante a terapia ou mesmo antes de três meses de sua suspensão, devendo ainda evitar contato próximo com indivíduos vacinados recentemente com essas vacinas. Nas situaçôes de pós-exposição, deverão receber soros ou imunoglobulinas específicas ${ }^{11,19}$.

Uma vez que os imunossupressores também possuem implicações relacionadas à gravidez e à lactação, as mulheres são um grupo populacional que merecem atenção especial acerca do uso dessa terapia.

Gestaçóes após o TF são classificadas como de alto risco devido ao aumento das taxas de complicaçóes que incluem hipertensão, pré-eclâmpsia e parto pré-termo. Para um melhor resultado, aconselha-se que a gestação seja planejada e adiada por pelo menos um a dois anos após o transplante ${ }^{1}$.

Todavia, eventos adversos foram observados em estudos de reprodução em animais expostos aos ICN, ao micofenolato e aos inibidores da mTOR. $\mathrm{O}$ micofenolato é o único destes que possui evidência reconhecida a partir de estudos em humanos no 
desenvolvimento de abortos no primeiro trimestre e malformações congênitas ${ }^{10,11}$. Assim, o aconselhamento materno às usuárias do micofenolato em idade fértil é de fundamental importância, discutindo-se opçóes de contracepção adequadas, incluindo a abstinência sexual, dispositivos intrauterinos, laqueadura tubária e vasectomia do parceiro ${ }^{14}$, já que a eficácia dos contraceptivos hormonais pode ser reduzida por esse fármaco ${ }^{10}$.

Com relação à lactação, as mulheres em uso dos ICN, do micofenolato ou dos inibidores da mTOR devem evitar essa prática, já que, apesar de apenas os ICN serem reconhecidamente excretados no leite materno, todos possuem potencial de reaçôes adversas graves no lactente ${ }^{10,11}$.

Dessa forma, a provisão de informaçóes é considerada uma intervenção terapêutica eficaz que contribui para os resultados do transplante e faz parte do plano de cuidados de enfermagem ${ }^{3}$. Assim, é fundamental compreender que o papel do enfermeiro no manejo dos imunossupressores transcende o ambiente hospitalar, e por isto, ensinar o paciente e a família, esta como uma unidade de cuidado, a respeito das medidas de promoção da saúde é fundamental para a manutenção do sucesso do transplante.
O paciente e a família devem compreender porque eles devem aderir de forma continua ao regime terapêutico, com ênfase sobre os métodos de administração, justificativas e efeitos adversos esperados dos agentes imunossupressores prescritos. Para evitar erros, o enfermeiro fornece instruçôes verbais, bem como por escrito sobre quando e como tomar os medicamentos, além de fornecer instruçóes sobre sinais e sintomas indicativos dos problemas que precisam de consulta com a equipe de transplante ${ }^{20}$.

A partir dessa perspectiva, apresentam-se no Quadro 7 as principais orientaçóes relacionadas ao uso dos imunossupressores a serem informadas ao paciente e à sua família durante a internação, alta hospitalar e consultas ambulatórias.

De fato, receptores de TF que vivenciam maiores níveis de eventos adversos relacionados aos imunossupressores apresentam maiores níveis de não adesão à terapia $^{7}$. No entanto, intervir preventivamente através do processo de educação em saúde favorece o aumento da satisfação e qualidade de vida, a melhoria da continuidade dos cuidados no domicílio, a diminuição da ansiedade e das possíveis complicaçóes, a maximização da independência e do empoderamento e consequentemente a adesão ao plano terapêutico proposto ${ }^{21}$.

Quadro 7: Principais orientações em saúde aos pacientes e família quanto ao uso da terapia imunossupressora.

\begin{tabular}{|c|c|}
\hline Imunossupressor & Orientaçóes \\
\hline $\begin{array}{c}\text { Comum a todas as } \\
\text { classes }\end{array}$ & $\begin{array}{l}\text { - Evitar tomar vacinas vivas, ao menos que indicado pela equipe de transplante, ou entrar em contato com } \\
\text { pessoas recém-vacinadas; } \\
\text { Limitar a exposição solar e a raios UV e usar protetor solar (mínimo fator 30) para reduzir o risco de câncer de } \\
\text { pele; } \\
\text { - Reduzir os riscos de infecçóes oportunistas: utilizar máscara nos primeiros meses pós-transplante; evitar aglo- } \\
\text { meraçóes e contato com pessoas com doenças infectocontagiosas; e manter uma adequada higienizaçáo das } \\
\text { mãos; } \\
\text { - Comunicar imediatamente qualquer sinal ou sintoma de infecção. }\end{array}$ \\
\hline $\begin{array}{l}\text { Corticosteroides } \\
\text { (Prednisona) }\end{array}$ & $\begin{array}{l}\text { - Podem causar náuseas, vômitos, diarreia, úlceras pépticas, atraso do crescimento (pediátrico), cicatrização } \\
\text { prejudicada, edema, osteoporose, ansiedade, depressão, euforia, irritabilidade, dor de cabeça, insônia, visão } \\
\text { dupla, catarata e glaucoma; } \\
\text { - } \quad \text { Relatar problemas com o controle glicêmico; } \\
\text { - Tomar o medicamento com alimentos ou leite para minimizar os efeitos gastrintestinais; } \\
\text { - } \quad \text { Evitar interrupção súbita da droga. }\end{array}$ \\
\hline $\begin{array}{l}\text { Inibidores da } \\
\text { calcineurina }\end{array}$ & $\begin{array}{l}\text { - Pode causar diarreia, náusea, dor abdominal, hipertensão, hiperglicemia, dores de cabeça, prurido e eritema } \\
\text { (Tacrolimo); } \\
\text { - Pode causar hipertensão, disfunção renal, hirsutismo, diarreia, náuseas, vômitos, dor de cabeça, tremor ou } \\
\text { aumento gengival (Ciclosporina); } \\
\text { - } \quad \text { Relatar sinais e sintomas de hiperglicemia ou hipercalemia; } \\
\text { - } \quad \text { Relatar alteraçóes visuais, do estado mental, convulsóes ou tremores; } \\
\text { - } \quad \text { Evitar consumir álcool e toranja* durante a terapia. }\end{array}$ \\
\hline
\end{tabular}


Quadro 7: Continuação.

\begin{tabular}{|c|c|}
\hline Imunossupressor & Orientaçóes \\
\hline Antiproliferativos & $\begin{array}{l}\text { - Podem causar constipação, diarreia, náuseas, vômitos, dispepsia, infecção urinária, insônia, dor de cabeça e } \\
\text { dor pós-operatória; } \\
\text { - } \\
\text { Evitar engravidar. Recomendar métodos contraceptivos adequados, evitando o uso de contraceptivos } \\
\text { hormonais; } \\
\text { - Relatar sinais de hematomas inesperados, sangramentos ou qualquer outra manifestação de supressão da } \\
\text { medula óssea; } \\
\text { - Tomar o medicamento em jejum ou com alimentos, porém, deve-se seguir sempre a mesma forma de adminis- } \\
\text { tração para evitar oscilações dos níveis séricos; } \\
\text { Evitar o uso concomitante de antiácidos que contenham magnésio e hidróxido de alumínio. }\end{array}$ \\
\hline $\begin{array}{c}\text { Inibidores da } \\
\text { mTOR }\end{array}$ & 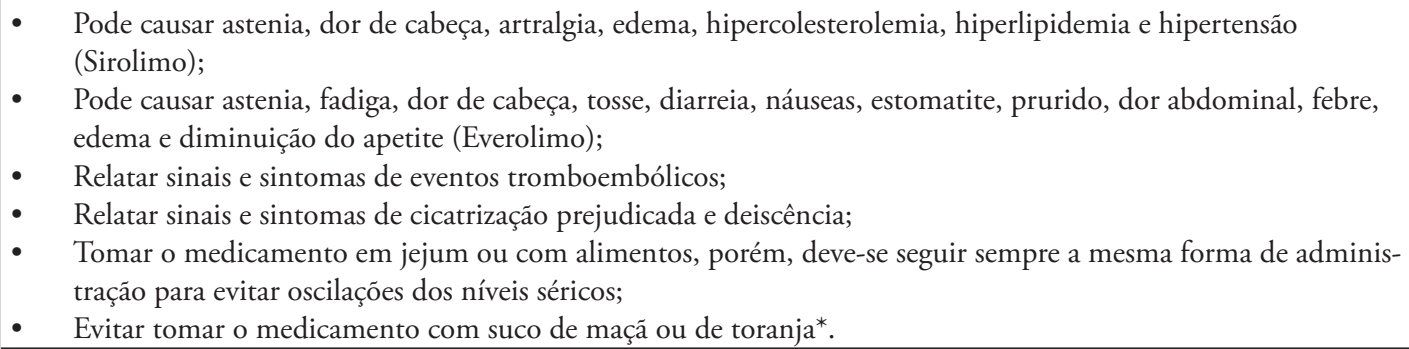 \\
\hline
\end{tabular}

Legenda: UV: Ultravioletas.

*Também conhecida como grapefruit, é uma fruta cítrica híbrida resultante do cruzamento do pomelo com a laranja.

\section{Conclusão}

Assim, a partir da caracterizaçáo dos imunossupressores utilizados no TF, foi possível observar que cada fármaco apresenta suas particularidades no que se referem a: suas aplicaçōes no transplante, efeitos farmacológicos, efeitos adversos e interaçóes medicamentosas, exigindo, para seu adequado manejo, profissionais de enfermagem embasados cientificamente no que concerne às suas características e aos seus cuidados relacionados, a fim de garantir uma terapia segura e eficaz, tal como respaldar o paciente com orientaçóes pertinentes, garantindo assim, seu empoderamento no próprio processo de cuidar.

Percebeu-se ainda, com base na revisão realizada nesse estudo, que ainda existem poucos estudos na literatura que se dedicam aos cuidados de enfermagem relacionados à terapia imunossupressora no transplante de órgãos e tecidos. Assim, considera-se de suma importância o desenvolvimento de pesquisas nessa área, a fim de fundamentar a prática clínica da equipe de enfermagem do transplante, assegurando, assim, uma prática baseada em evidências.

\section{Referências}

1. Moini M, Schilsky ML, Tichy EM. Review on immunosuppression in liver transplantation. World J Hepatol. 2015;7(10):1355-68.
2. Meirelles Júnior RF, Salvalaggio P, Rezende MB, Evangelista AS, Guardia BD, Matielo CE, et al. Transplante de fígado: história, resultados e perspectivas. Einstein. 2015;13(1):149-52.

3. Mendes KDS, Rossin FM, Ziviani LC, Castro-e-Silva $\mathrm{O}$, Galvão CM. Necessidades de informação de candidatos ao transplante de fígado: o primeiro passo do processo ensino-aprendizagem. Rev Gaucha Enferm. 2012;33(4):94-102.

4. Associação Brasileira de Transplante de Órgãos (BR); Registro Brasileiro de Transplantes. Dimensionamento dos transplantes no Brasil e em cada estado. São Paulo: Associação Brasileira de Transplante de Órgáos, 2014.

5. Kern B, Sucher R. Clinical immunosuppression in solid organ and composite tissue allotransplantation. In: Kapur $S$, Portela MB, editors. Immunosuppression - role in health and diseases. [s.l.]: InTech; 2012. p. 423-32.

6. Jara P. Inmunosupresión en niños con trasplante hepático. Rev Gastrohnup. 2010;12(2) Suppl 1:S31-7.

7. Wang C, Wang G, Yi H, Tan J, Xu C, Fang X, et al. Symptom experienced three years after liver transplantation under immunosuppression in adults. PLoS One. 2013;8(11):1-9.

8. Silva LR, Martins TSS, Silvino ZR, Mello LP, Castro MA, Andrade ENM. Reaçóes adversas medicamentosas na unidade pediátrica: o conhecimento da equipe de enfermagem. Rev Rene. 2011;12(1):144-9.

9. Ministério da Saúde (BR); Secretaria de Ciência; Tecnologia e Insumos Estratégicos. Relação Nacional de Medicamentos Essenciais: RENAME 2014. Brasília: Ministério da Saúde; 2015. 
10. Micromedex Healthcare Series [Internet]. Colorado: Greenwood Village; [citado em 2015 Set 29]. Disponível em: https://www.thomsonhc.com/

11. Wolters Kluwer Health. Uptodate [Internet]. [citado em 2015 Set 29]. Disponível em: https://www.uptodate.com/

12. Van Sandwijk MS, Bemelman FJ, Ten Berge IJM. Immunosuppressive drugs after solid organ transplantation. Neth J Med. 2013;71(6):281-9.

13. Rodríguez-Perálvarez M, De La Mata M, Burroughs AK. Liver transplantation: immunosuppression and oncology. Curr Opin Organ Transplant. 2014;19(3):253-60.

14. Enderby C, Keller CA. An overview of immunosuppression in solid organ transplantation. Am J Manag Care. 2015;21 Suppl 1:S12-23.

15. Hardinger KL, Brennan DC. Novel immunosuppressive agents in kidney transplantation. World J Transplant. 2013;3(4):68-77.

16. Bressan AL, Souto RS, Fontenelle E, Gripp AC. Imunossupressores na dermatologia. An Bras Dermatol. 2010;85(1):9-22.
17. Martins TSS, Silvino ZR, Silva LR. Eventos adversos na terapia farmacológica pediátrica: revisão integrativa da literatura. Rev Bras Enferm. 2011;64(4):745-50.

18. Jacomini LCL, Silva NA. Interaçóes medicamentosas: uma contribuição para o uso racional de imunossupressores sintéticos e biológicos. Rev Bras Reumatol. 2011;51(2):161-74.

19. Ministério da Saúde (BR); Secretaria de Vigilância em Saúde; Departamento de Vigilância das Doenças Transmissíveis. Manual de normas e procedimentos para vacinação. Brasília: Ministério da Saúde; 2014.

20. Jorge DBR, Popov DCS. Aspectos fundamentais da assistência de enfermagem no transplante hepático. Rev Enferm UNISA. 2011;12(2):142-7.

21. Mendes KDS, Castro e Silva O, Ziviani LC, Rossin FM, Zago MMF, Galvão CM. Intervenção educativa para candidatos ao transplante de fígado. Rev Latino-Am Enfermagem. 2013;21(1):7 telas.

\section{Como citar este artigo:}

Sá RC, Soares CRS. Terapia imunossupressora no transplante de fígado: constribuição para a enfermagem. Rev. Aten. Saúde. 2016;14(50):111-125. 